\title{
Differences of Susceptibility of Five Triatomine Species to Pyrethroid Insecticides - Implications for Chagas Disease Vector Control
}

\author{
Alfredo Martins de Oliveira Filho \\ Núcleo de Pesquisas de Produtos Naturais, Laboratório de Biologia, Bloco H, Universidade Federal do \\ Rio de Janeiro, 21941-590 Rio de Janeiro, RJ, Brasil
}

As pyrethroids are presently the favored group of insecticides to control triatomines, we performed a series of bioassays to determine the intrinsic activity of some of the main compounds used in the control campaigns, against five of the main species of triatomines to be controlled.

Comparing the insecticides it can be seen that lambdacyhalothrin is more effective than the other three pyrethroids, both considering the LD50 and 99 for all the three species with comparable results. On Triatoma infestans the LD50 of lambdacyhalothrin was followed by that of alfacypermethrin, cyfluthrin and deltamethrin. On Rhodnius prolixus the sequence, in decreasing order of activity, was lambdacyhalothrin, alfacypermethrin, deltamethrin and cyfluthrin. Some modifications can be seen when we compare the LD99, that has more to see to what happens in the field. T. brasiliensis showed to be as sensible to lambdacyhalothrin as $\mathrm{T}$. infestans, the most susceptible for this product. By the other side $\mathrm{T}$. sordida is the least susceptible considering the LD99 of this insecticide.

Key words: triatomine - insecticides - Chagas disease - Triatoma - Panstrongylus - Rhodnius

At present the elimination of vectorial transmission of Chagas disease is assumed as a priority for most governments of Latin American countries. The WHO/TDR Southern Cone Initiative, involving Argentina, Bolivia, Brazil, Chile, Paraguay, Peru, and Uruguay, where there are 11 millions of infected persons and 50 millions at risk of acquiring the disease, proposed to eradicate Triatoma infestans of their territories (except for Bolivia where this species is found in silvatic habitats). This commitment lead to significant reductions of incidence of the disease accordingly to WHO data (Moncayo 1999).

Recently two other country blocks interested in the control of transmission appeared. The Initiative of the Andean countries, involving Colombia, Ecuador, Peru, and Venezuela, where 5-6 million infected individuals and 25 million at risk can be found. The other block was organized by Central American countries, i.e., Costa Rica, El Salvador, Guatemala, Honduras, Mexico, Nicaragua and

\footnotetext{
This project was sponsored by WHO/UNDP/World Bank, WHO Special Programme for Research and Training in Tropical Diseases/TDR, CEPG-UFRJ.

Fax: +55-21-270.3883

E-mail: vectorcontrol@nppn.ufrj.br

Received 9 June 1999

Accepted 9 August 1999
}

Panama. The main vectors in these two areas is Rhodnius prolixus (Guhl 1999, Ponce 1999).

In Brazil the eradication of T. infestans goal is almost achieved and growing attention is being paid to other species, considered as secondary vectors in the past, like T. sordida, T. brasiliensis and in a few areas, Panstrongylus megistus.

A series of laboratory and field assays performed by our group on the susceptibility of many triatomines species to organochlorines, organophosphates, carbamates and a few pyrethroids have shown marked differences between species (Oliveira Filho 1997, 1998a, 1998b, Oliveira Filho et al. 1981, 1982) As pyrethroids are presently the favored group of insecticides to control triatomines, we performed a series of bioassays to determine the intrinsic activity of some of the main compounds used in the control campaigns, against five of the main species of triatomines to be controlled. The objective was the straight comparison of the active principles, dissolved in acetone solutions and applied topically, envisaging the determination of lethal dosis of non-formulated compounds.

\section{MATERIALS AND METHODS}

Technical products, received from ICI, were certified by gas chromatography analysis performed at the NPPN, as containing lambdacyhalothrin $96.3 \%$, (ICI) - deltamethrin $99.9 \%$ (Rousell-Uclaf), cyfluthrin 93.9\% (Bayer) and alfacyper-methrin 96.2\% (Shell). 
The triatomines species used were $T$. infestans, T. brasiliensis, T. sordida, P. megistus and $R$. prolixus. The laboratory colonies were maintained at $27 \pm 2^{\circ} \mathrm{C}, 70 \pm 10 \%$ R.H., $12: 12 \mathrm{hr}$ light/dark periods and given a fortnightly opportunity to feed. The nymphs were synchronized chronologically and physiologically, i.e., only those that moulted to 5th instar in the same week and were fed in the next one, absorbing a similar amount of blood, were tested. Time of the test was between 14 and 21 days in the 5th instar.

The treatment consisted in the topical application, in the dorsal part of the abdomen of 5th instar nymphs, of $1 \mu \mathrm{l}$ of the insecticide solution in acetone, using a Hamilton mycrosyringe and a mycroaplicator. Ten nymphs were treated each time for each concentration and the test was repeated at least once in another occasion. Insects in the control group were treated with the same amount of solvent used for those that received the active ingredient. The insects were then maintained in clean glass jars fitted with filter paper roosts and closed with nylon netting. The readings were performed at $1,2,3,7,14$ and 21 days after treatment, recording insects alive, intoxicate, moribund and dead. Moribund insects were considered as dead at the time of reading if they do not recovered after. The percent mortalities, obtained with each dose, three days after treatment, were plotted in a log-probit graphic with the help of a computer program (SPSS). At least three plots between 10 and 90\% were obtained. The LD50 and LD99 were then obtained together with the $95 \%$ confidence upper and lower limits.

\section{RESULTS AND DISCUSSION}

Table reports the results obtained for the four insecticides tested in the three species belonging to three different genera bioassayied, plus the results of lambdacyhalothrin for T. sordida and $T$. brasiliensis. Figure expresses, in a more understandable way, the comparisons between insecticides and species. Considering the three species tested for all the insecticides $R$. prolixus is the most susceptible (except for lambdacyhalothrin for which $T$. infestans is the most susceptible), followed by $T$. infestans and P. megistus. This last species is the least susceptible by far, even considering the weight in $\mu \mathrm{g}$ of active ingredient $/ \mathrm{mg}$ of live weight.

Comparing the insecticides it can be seen that lambdacyhalothrin is more effective than the other three pyrethroids, both considering the LD50 and 99 for all the three species with comparable results. On T. infestans the LD50 of lambdacyhalothrin was followed by that of alfacypermethrin, cyfluthrin and deltamethrin. On $R$. prolixus the sequence, in decreasing order of ac-

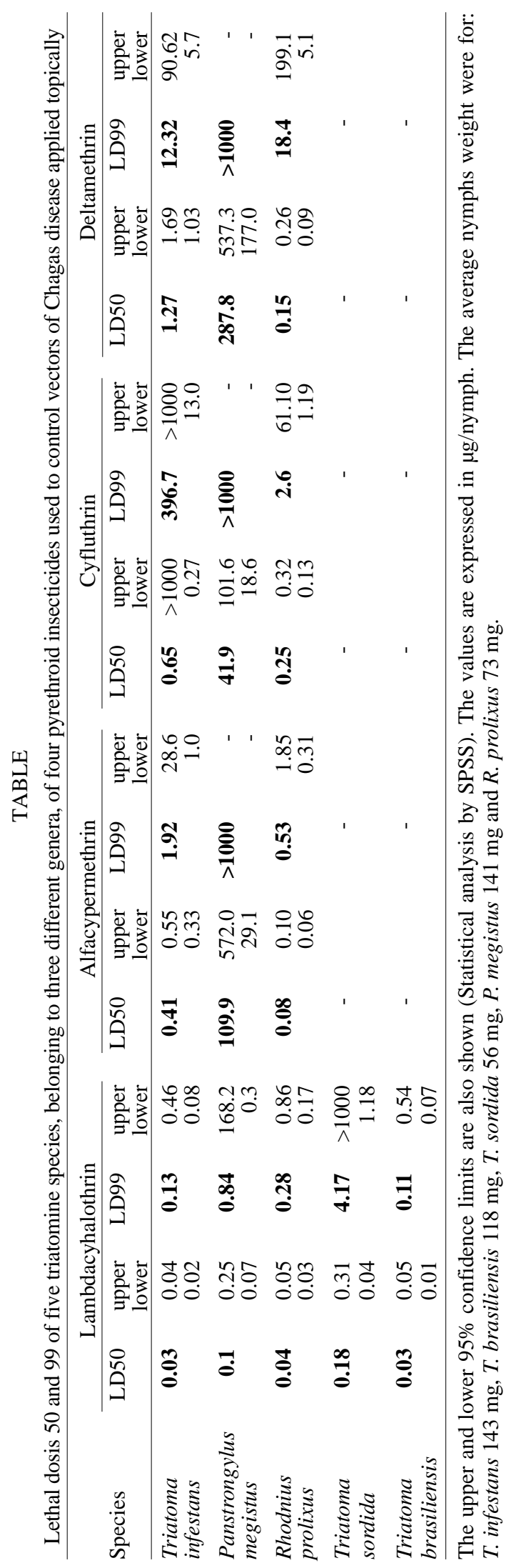




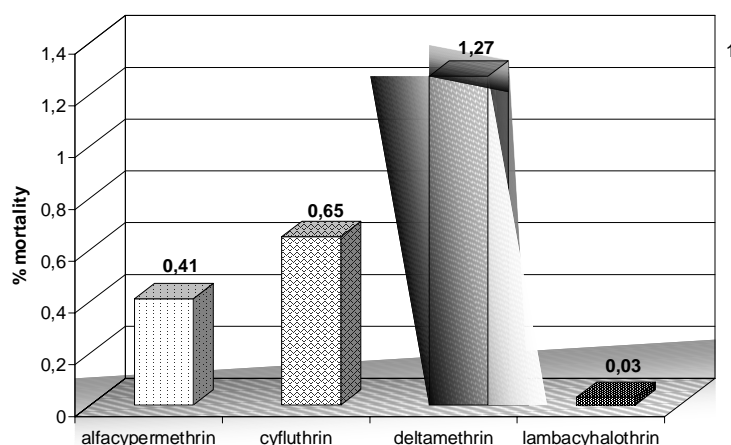

1 - LD 50

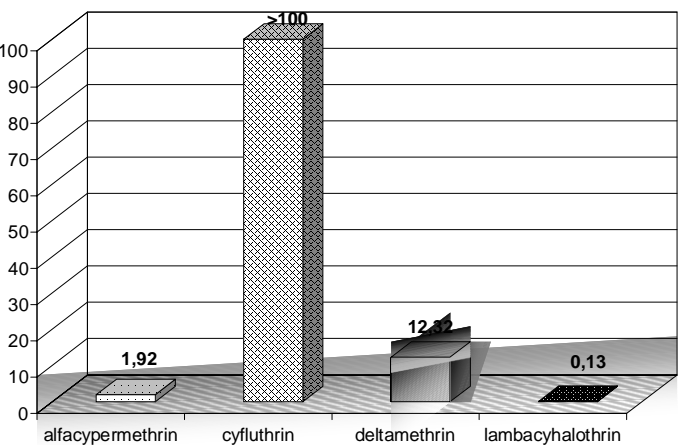

2 - LD 99

Triatoma infestans

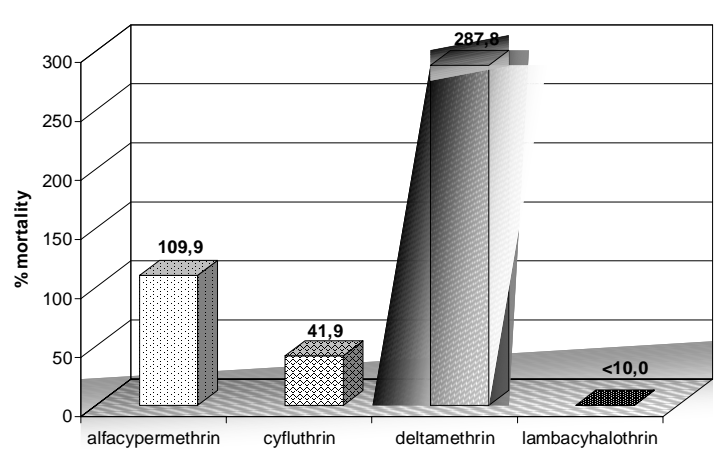

3 - LD 50

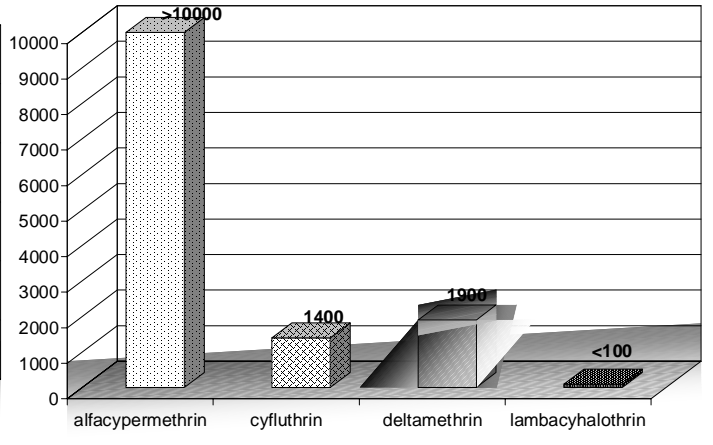

4 - LD 99

Panstrongylus megistus

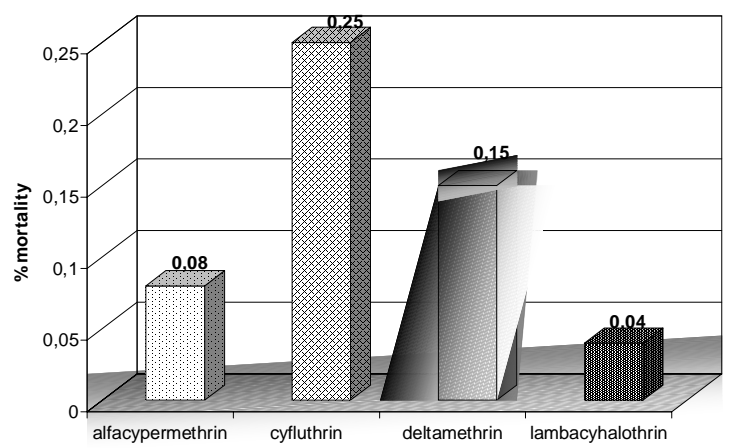

5 - LD 50

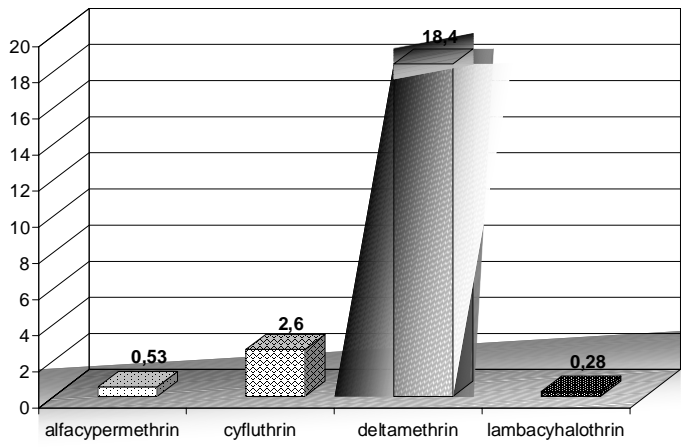

6 - LD 99

Rhodnius prolixus

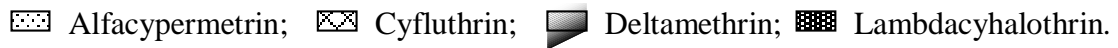

Comparison of topical LD50 and DL99 of four pyrethroid insecticides obtained for three triatomine species.

tivity, was lambdacyhalothrin, alfacypermethrin, deltamethrin and cyfluthrin. Some modifications can be seen when we compare the LD99, that has more to see to what happens in the field. $T$. brasiliensis showed to be as sensible to lambdacyhalothrin as T. infestans, the most susceptible for this product. By the other side $T$. sordida is the least susceptible considering the LD99.

Three out of four of these pesticides has shown little effect on P. megistus and, by these results, should not be recommended when the control campaign is against this species - alfacypermethrin, cyfluthrin and deltamethrin. Having in mind these 
significant differences between products we tested again these species using the LD50 as the parameter of comparison. The results obtained were quite near $50 \%$ mortality, confirming that these hudge differences really exists.

Problably these different performances of technical products applied topically cannot be transferred to field situations, where formulated products interacts with the insect for longer time and suffer the influence of environmental factors like the reactivity of the substract, light, temperature, humidity, etc. However the intrinsic difference of toxicity will certainly result in different doses to be recommended for field use.

\section{ACKNOWLEDGEMENTS}

To the NPPP staff, Marli T Vieira de Mello, Celso E dos Santos, EB Lustosa, Elizabete G Costa, Orbino C Damião and Joaquim J Souza for their permanent assistance and Dr Antonio Jorge R Silva and Elimar Brandt for the chemical analysis.

\section{REFERENCES}

Guhl F. Interruption of Chagas disease transmission in the Andean countries: Colombia. Mem Inst Oswaldo Cruz (in this volume).
Moncayo A 1999. Progress towards interruption of transmission of Chagas disease. Mem Inst Oswaldo Cruz (on this volume)

Oliveira Filho AM 1997. Uso de nuevas herramientas para el control de triatominos en diferentes situaciones entomológicas en el continente americano. Rev Soc Bras Med Trop 30: 41-46.

Oliveira Filho AM 1988a. Development of insecticide formulations and determination of dosages and application schedules to fit specific situations. Rev Arg Microbiol 20 (Suppl.): 39-48.

Oliveira Filho AM 1988b. New prospectives in the fight against triatomines - results of a large scale field trial of insecticides and formulations, p. 30-37. Proceedings V Reunião Pesq Apl Doença Chagas, Araxá, MG, Brasil.

Oliveira Filho AM, Pinchin R, Melo MTV, Silva WS, Santos CE, Henney MA, Figueiredo MJ 1981. Laboratory screening of 23 insecticides for triatomine control - determination of LD50 and LD95 for Panstrongylus megistus. Ciênc Cult 33 (Suppl.): 455.

Oliveira Filho AM, Santos CE, Figueiredo MJ, Melo MTV, Henney MA, Silva WS 1982. Ensaios preliminares de suscetibilidade a BHC de triatomíneos brasileiros, através da técnica de papéis impregnados. Ciênc Cult 34 (Suppl.): 728.

Ponce C. Elimination of the vectorial transmission of Chagas disease in Central American Countries: Honduras. Mem Inst Oswaldo Cruz (in this volume). 